\title{
Influence of Job Embeddedness and Resilience on Turnover Intention in Dental Hygienists
}

\author{
$\mathrm{Ji}-$ Min Hwang ${ }^{1}$ and Ji-Hyoung $\mathrm{Han}^{2, \dagger}$ \\ 1Department of Dental Hygiene, Baekseok Culture University, Cheonan 31065, \\ ${ }^{2}$ Department of Dental Hygiene, Suwon Science College, Hwaseong 18516, Korea
}

\begin{abstract}
Background: Maintaining a skilled workforce by minimizing the turnover of competent dental hygienists is very important for securing dental competitiveness. Therefore, it is necessary to find a predictor of turnover and lower turnover intention. To understand dental hygienist turnover, it is necessary to study the resilience, a positive factor of personal characteristics and job embeddedness that induces residual tissue. The purpose of this study was to investigate the effect of dental hygienists' job embeddedness and resilience on turnover intention.

Methods: A survey was conducted on licensed dental hygienists nationwide, from March 19 to July 19, 2020. T-test and one way ANOVA analysis were performed to compare the job embeddedness, resilience, and turnover intention according to the general characteristics. Pearson's correlation analysis was performed to identify the correlation between job embeddedness, resilience, and turnover intention. Multiple regression analysis was performed to determine the effect on the turnover intention.

Results: Job embeddedness was the highest with link and resilience scoring 3.57 and 4. 16, respectively. The turnover intention scored 3.53. Among the general characteristics, age, marriage, total dental clinic career, education degree, and position showed statistically significant differences in job embeddedness, resilience, and turnover intention. Suitability, link, and sacrifice of job embeddedness were shown to affect the degree of turnover intention, with an explanatory power of 26. $2 \%$.

Conclusion: In order to reduce the dental hygienists' turnover intention, job embeddedness and resilience should be increased. Thus, measures should be undertaken for professional and systematic program development and human resources management.
\end{abstract}

Key Words: Dental hygienists, Job embeddedness, Resilience, Turnover

\section{Introduction}

A key element of hospital organization is human resources; securing and maintaining this is important for hospital growth and development ${ }^{1-3)}$. Dental hygienists are professional human resources that play a pivotal role in the promotion of oral health in the public and influence the determination of productivity and quality of dental services. Around $45.9 \%(88,000)$ of dental hygienist license holders are active, and more than 5,000 are licensed annually, but they are having difficulty in manpower supply and demand due to turnover ${ }^{4)}$. Turnovers happen in $45.8 \%$ of dental hygienists, which is almost half of the total ${ }^{5)}$. Maintaining a skilled workforce by minimizing the turnover of competent dental hygienists is very important for securing dental competitiveness ${ }^{6}$. Therefore, it is necessary to find a predictor of turnover and lower turnover intention. Job embeddedness and resilience are being discussed as new variables for turnover ${ }^{7,8)}$. Job embeddedness refers to the degree to which an organizational member is rooted in the organization in relation to the job ${ }^{9)}$. Job embeddedness expresses a high degree of relevance to be buried deeply in something, or in simpler terms, this is why an organization's members choose to 
remain $^{7)}$. Resilience is a concept that includes the ability of an individual to overcome stress or adversity, adapt positively, and grow as an individual ${ }^{10)}$. Dental hygienists reportedly experience high stress, namely due to interpersonal conflict, physical environment, organizational system, job demand, and lack of reward ${ }^{11}$. In organizational culture, resilience is needed to mature human capital, control individual feelings, and overcome stress. These two factors lower the turnover intention of dental hygienists.

Due to the shortage of health care workers, other studies on turnover have been ongoing ${ }^{2,3,6-8)}$. However, studies involving job embeddedness and resilience in dental hygienists are insufficient. To understand dental hygienist turnover, it is necessary to study resilience, a positive factor of personal characteristics, and job embeddedness, which is an individual's reason for remaining in their job. This study aims to provide basic data for efficient manpower management by understanding the effects of job placement and the resilience of dental hygienists on their turnover intentions.

\section{Materials and Methods}

\section{Subjects and methods}

This study was conducted by randomly sampling and surveying licensed dental hygienists across the country. The survey was conducted from March 19 to July 19, 2020. The purpose of the research were explained to the research subjects, and confidential information were investigated after receiving written consent from the subjects, to comply with research ethics. The sample size was obtained from the G Power 3.1 program, and 221 people were calculated for correlation and regression analysis based on an effect size of 0.15 , significance level of 0.05 , and statistical power of 0.8 .

\section{Variables used in analysis}

A total of 9 questions were used to investigate the following general characteristics: age, sex, marriage, religion, total dental clinic career, current dental clinic carrier, educational degree, position, and monthly salary. Job embeddedness was based on the definition set by
Mitchell et al. ${ }^{9)}$, and its sub-domains consisted of 18 questions composed of 8 questions for fit, 4 questions for link, and 6 questions for sacrifice. Fit is the suitability of the subject to being a dentist. Link refers to the interaction between departments or colleagues. Lastly, sacrifice means the patient's sacrifice for the dental clinic. The answers to the questions were measured on a five-point scale ranging from five points for "very much so" to one point for "not at all." The reliability of the research tool was Cronbach's $\alpha=0.912$. The questions for resilience was developed by Connor and Davidson ${ }^{12)}$ and translated into Korean by Baek ${ }^{13)}$. The sub-domains consisted of a total of 25 questions: 9 for toughness, 8 for patience, 4 for positive tendency, 2 for support, and 2 for spirituality. The answers to the questions were measured on a five-point scale ranging from five points for "very much so" to one point for "not at all." The reliability of the research tool was Cronbach's $\alpha=0.910$. The turnover intention consisted of five questions by Moon and $\mathrm{Han}^{2)}$ modified and supplemented by the tools developed by Mobley ${ }^{14)}$. A Likert five-point scale was used, and Cronbach's $\alpha$ value was 0.847 .

\section{Data analysis}

General characteristics were analyzed for frequency, and job embeddedness, resilience, and turnover intention were analyzed for technical statistics. The t-test and one-way ANOVA analysis were performed to compare job embeddedness, resilience, and turnover intention according to general characteristics. Levene statistics were

Table 1. Job Embeddedness, Resilience, Turnover Intention

\begin{tabular}{cc}
\hline Variable & Mean \pm standard deviation \\
\hline Job embeddedness & $3.35 \pm 0.608$ \\
Fit & $3.47 \pm 0.719$ \\
Link & $3.57 \pm 0.743$ \\
Sacrifice & $3.06 \pm 0.624$ \\
Resilience & $3.58 \pm 0.506$ \\
Toughness & $3.36 \pm 0.632$ \\
Patience & $3.74 \pm 0.601$ \\
Positive tendency & $3.57 \pm 0.657$ \\
Support & $4.16 \pm 0.810$ \\
Spirituality & $3.37 \pm 0.709$ \\
Turnover intention & $3.53 \pm 0.873$ \\
\hline
\end{tabular}


used to test for equal variances, and differences between groups were analyzed through the Scheffe follow-up test. Pearson's correlation analysis was performed to identify the correlation between job embeddedness, resilience, and turnover intention. Multiple regression analysis was performed to determine the effect on turnover intention, and the significance level of all analyses was set to 0.05 . The data were analyzed using the software for statistical analysis, PASW statistics ver. 18.0 (IBM Corp., Armonk,
NY, USA).

\section{Results}

1. Job embeddedness, resilience, and turnover intention

Job embeddedness was the highest in link with a score of 3.57, and sacrifice was the lowest at 3.06. Resilience had scores of 4.16 in support, 3.74 in patience, and 3.57 in

Table 2. Differences in Job Embeddedness, Resilience and Turnover Intention according to General Characteristics

\begin{tabular}{|c|c|c|c|c|c|c|c|c|c|c|}
\hline \multirow[b]{2}{*}{ Characteristic } & \multirow[b]{2}{*}{ Category } & \multirow[b]{2}{*}{$\mathrm{n}(\%)$} & \multicolumn{3}{|c|}{ Job embeddedness } & \multicolumn{3}{|c|}{ Resilience } & \multicolumn{2}{|c|}{ Turnover intention } \\
\hline & & & $\begin{array}{c}\text { Mean } \pm \\
\text { standard } \\
\text { deviation }\end{array}$ & $\mathrm{p}$-value & Scheffe & $\begin{array}{c}\text { Mean } \pm \\
\text { standard } \\
\text { deviation }\end{array}$ & p-value & Scheffe & $\begin{array}{c}\text { Mean } \pm \\
\text { standard } \\
\text { deviation }\end{array}$ & p-value Scheffe \\
\hline \multirow[t]{3}{*}{ Age (y) } & $<30^{\mathrm{a}}$ & $133(60.2)$ & $3.28 \pm 0.536$ & 0.005 & $\mathrm{a}, \mathrm{b}<\mathrm{c}$ & $3.51 \pm 0.471$ & 0.015 & $\mathrm{a}<\mathrm{c}$ & $3.62 \pm 0.785$ & $0.004 \mathrm{a}<\mathrm{b}, \mathrm{c}$ \\
\hline & $30 \sim<40^{\mathrm{b}}$ & $59(26.7)$ & $3.35 \pm 0.673$ & & & $3.64 \pm 0.539$ & & & $3.56 \pm 0.991$ & \\
\hline & $\geq 40^{\mathrm{c}}$ & $29(13.1)$ & $3.68 \pm 0.690$ & & & $3.79 \pm 0.537$ & & & $3.04 \pm 0.867$ & \\
\hline \multirow[t]{2}{*}{ Sex } & Male & $5(2.3)$ & $3.35 \pm 0.925$ & 0.995 & & $3.66 \pm 0.434$ & 0.724 & & $3.60 \pm 1.067$ & 0.863 \\
\hline & Female & $216(97.7)$ & $3.35 \pm 0.602$ & & & $3.58 \pm 0.508$ & & & $3.53 \pm 0.871$ & \\
\hline \multirow[t]{3}{*}{ Marriage } & No & $170(76.9)$ & $3.26 \pm 0.566$ & $<0.001$ & & $3.51 \pm 0.484$ & $<0.001$ & & $3.62 \pm 0.839$ & 0.009 \\
\hline & Yes & $49(22.2)$ & $3.67 \pm 0.647$ & & & $3.82 \pm 0.484$ & & & $3.24 \pm 0.922$ & \\
\hline & Etc. & $2(0.9)$ & $3.83 \pm 0.392$ & & & $3.86 \pm 0.197$ & & & $2.60 \pm 0.848$ & \\
\hline \multirow[t]{2}{*}{ Religion } & Yes & $81(36.7)$ & $3.49 \pm 0.631$ & 0.010 & & $3.71 \pm 0.466$ & 0.003 & & $3.46 \pm 0.899$ & 0.409 \\
\hline & No & $140(63.3)$ & $3.27 \pm 0.581$ & & & $3.50 \pm 0.513$ & & & $3.57 \pm 0.858$ & \\
\hline \multirow{5}{*}{$\begin{array}{l}\text { Total dental } \\
\text { clinic career } \\
\text { (y) }\end{array}$} & $<1^{\mathrm{a}}$ & $25(11.3)$ & $3.40 \pm 0.609$ & 0.001 & $\mathrm{c}<\mathrm{e}$ & $3.69 \pm 0.504$ & $<0.001$ & $\mathrm{~b}<\mathrm{e}$ & $3.16 \pm 0.687$ & $<0.001 \mathrm{c}, \mathrm{d}>\mathrm{e}$ \\
\hline & $1 \sim<3^{b}$ & $55(24.9)$ & $3.28 \pm 0.473$ & & & $3.40 \pm 0.421$ & & & $3.65 \pm 0.713$ & \\
\hline & $3 \sim<5^{\mathrm{c}}$ & $44(19.9)$ & $3.16 \pm 0.560$ & & & $3.55 \pm 0.515$ & & & $3.90 \pm 0.887$ & \\
\hline & $5 \sim<10^{d}$ & $50(22.6)$ & $3.29 \pm 0.623$ & & & $3.52 \pm 0.500$ & & & $3.73 \pm 0.835$ & \\
\hline & $\geq 10^{\mathrm{e}}$ & $47(21.3)$ & $3.35 \pm 0.608$ & & & $3.83 \pm 0.505$ & & & $3.02 \pm 0.888$ & \\
\hline \multirow{5}{*}{$\begin{array}{l}\text { Dental clinic } \\
\text { carrier in } \\
\text { currently } \\
\text { (y) }\end{array}$} & $<1^{\mathrm{a}}$ & $60(27.1)$ & $3.27 \pm 0.645$ & $<0.001$ & $\mathrm{a}, \mathrm{b}, \mathrm{c}<\mathrm{e}$ & $3.64 \pm 0.486$ & 0.072 & & $3.40 \pm 0.898$ & $0.009 \mathrm{e}<\mathrm{b}$ \\
\hline & $1 \sim<3^{\mathrm{b}}$ & $82(37.1)$ & $3.23 \pm 0.502$ & & & $3.47 \pm 0.493$ & & & $3.73 \pm 0.756$ & \\
\hline & $3 \sim<5^{\mathrm{c}}$ & $38(17.2)$ & $3.33 \pm 0.606$ & & & $3.55 \pm 0.551$ & & & $3.64 \pm 0.934$ & \\
\hline & $5 \sim<10^{d}$ & $20(9.0)$ & $3.68 \pm 0.475$ & & & $3.71 \pm 0.461$ & & & $3.40 \pm 0.892$ & \\
\hline & $\geq 10^{\mathrm{e}}$ & $21(9.5)$ & $3.78 \pm 0.734$ & & & $3.76 \pm 0.510$ & & & $3.04 \pm 0.896$ & \\
\hline \multirow{3}{*}{$\begin{array}{l}\text { Education } \\
\text { degree }\end{array}$} & Associate $^{\mathrm{a}}$ & $102(46.2)$ & $3.21 \pm 0.610$ & $<0.001$ & $\mathrm{a}, \mathrm{b}<\mathrm{c}$ & $3.42 \pm 0.507$ & $<0.001$ & $\mathrm{a}<\mathrm{b}<\mathrm{c}$ & $3.70 \pm 0.841$ & $0.002 \mathrm{a}, \mathrm{b}>\mathrm{c}$ \\
\hline & Bachelor $^{\mathrm{b}}$ & $91(41.2)$ & $3.39 \pm 0.539$ & & & $3.66 \pm 0.450$ & & & $3.47 \pm 0.836$ & \\
\hline & $\begin{array}{l}\text { Master or } \\
\text { higher }^{c}\end{array}$ & $28(12.7)$ & $3.73 \pm 0.608$ & & & $3.89 \pm 0.479$ & & & $3.06 \pm 0.936$ & \\
\hline \multirow[t]{4}{*}{ Position } & Staffa & $154(69.7)$ & $3.20 \pm 0.542$ & $<0.001$ & $\mathrm{a}<\mathrm{b}, \mathrm{d}$ & $3.50 \pm 0.498$ & 0.001 & $a<d$ & $3.62 \pm 0.823$ & $0.009 \quad \mathrm{c}>\mathrm{d}$ \\
\hline & $\begin{array}{l}\text { Head of a } \\
\text { epartment }^{b}\end{array}$ & $27(12.2)$ & $3.76 \pm 0.663$ & & & $3.75 \pm 0.473$ & & & $3.32 \pm 1.054$ & \\
\hline & Team leader ${ }^{c}$ & $20(9.0)$ & $3.55 \pm 0.410$ & & & $3.68 \pm 0.364$ & & & $3.67 \pm 0.768$ & \\
\hline & Etc. $^{\mathrm{d}}$ & $20(9.0)$ & $3.80 \pm 0.672$ & & & $3.90 \pm 0.559$ & & & $2.99 \pm 0.893$ & \\
\hline \multirow{5}{*}{$\begin{array}{l}\text { Monthly } \\
\text { salary } \\
\text { (10,000 won) }\end{array}$} & $<180^{\mathrm{a}}$ & $27(12.2)$ & $3.45 \pm 0.712$ & 0.002 & $\mathrm{~b}, \mathrm{c}, \mathrm{d}<\mathrm{e}$ & $3.64 \pm 0.392$ & 0.098 & & $3.22 \pm 0.783$ & 0.012 \\
\hline & $180 \sim<200^{\mathrm{b}}$ & $48(21.7)$ & $3.29 \pm 0.573$ & & & $3.46 \pm 0.505$ & & & $3.53 \pm 0.731$ & \\
\hline & $200 \sim<250^{\mathrm{c}}$ & $73(33.3)$ & $3.25 \pm 0.564$ & & & $3.53 \pm 0.539$ & & & $3.69 \pm 0.905$ & \\
\hline & $250 \sim<300^{\mathrm{d}}$ & $48(21.7)$ & $3.29 \pm 0.529$ & & & $3.65 \pm 0.464$ & & & $3.66 \pm 0.894$ & \\
\hline & $\geq 300^{\mathrm{e}}$ & $25(11.3)$ & $3.79 \pm 0.655$ & & & $3.76 \pm 0.549$ & & & $3.12 \pm 0.921$ & \\
\hline
\end{tabular}

Data was analysed by t-test and one-way ANOVA statistics. 
positive tendency, with toughness scoring the lowest at 3.36. The turnover intention had a score of 3.53 (Table 1).

\section{Differences in job embeddedness, resilience, and turnover intention according to general characteristics}

Among the general characteristics, there were statistically significant differences in job embeddedness, resilience, and turnover intention according to age, marriage, total dental clinic career, educational degree, and position. The higher the age and level of education, the higher the job embeddedness $(p=0.005, p<0.001)$ and resilience $(p=0.015, p<0.001)$ and the lower the degree of turnover intention $(p=0.004, p=0.002)$. These variables also differed depending on marriage status; unmarried people showed lower job embeddedness $(p<0.001)$, lower resilience $(\mathrm{p}<0.001)$, and a higher degree of turnover intention $(p=0.009$, Table 2$)$.

\section{Correlation between the sub-domains of job embeddedness, resilience, and turnover intention}

Sacrifice and fit (0.701), patience and toughness (0.682), link and fit (0.604), and sacrifice and link (0.582) showed high positive correlations between each other. However, there was a negative correlation between turnover intentions and the sub-domains of job embeddedness and resilience. Among them, turnover intention and fit
$(-0.484)$ showed the lowest negative correlation. Sacrifice $(-0.414)$ and toughness $(-0.275)$ showed a low negative correlation $(\mathrm{p}<0.05$, Table 3$)$.

\section{Factors affecting turnover intentions}

As a result of analyzing multicollinearity between independent variables prior to regression analysis, the tolerance limit was 0.450 to 0.586 , which was 0.1 or more.

The variance inflation factors was 1.708 to 2.223 , which did not exceed 10, indicating that there was no problem in multicollinearity between independent variables.

It was found that the fit, link, and sacrifice of job embeddedness were factors affecting turnover intention. The explanatory power was $26.2 \%$ and the DurbinWatson index was 1.993 , which was close to 2 , indicating that there was no autocorrelation of the error term. The regression model was found to be statistically significant $(\mathrm{F}=26.973, \mathrm{p}<0.001$, Table 4).

\section{Discussion}

This study attempted to investigate the effect of job embeddedness and resilience on turnover intention in dental hygienists. The main implications according to the research results are as follows.

First, we examined the job embeddedness, resilience, and turnover intention of dental hygienists. Job embeddedness scored 3.35. Regarding the sub-domains, link scored the

Table 3. Correlation between Sub-Domains of Job Embeddedness and Resilience and Turnover Intention

\begin{tabular}{|c|c|c|c|c|c|c|c|c|c|c|}
\hline Variable & & A & B & $\mathrm{C}$ & $\mathrm{D}$ & $\mathrm{E}$ & $\mathrm{F}$ & $\mathrm{G}$ & $\mathrm{H}$ & I \\
\hline \multirow[t]{3}{*}{ Job embeddedness $^{\mathrm{a}}$} & A & 1 & & & & & & & & \\
\hline & B & $0.604 * * *$ & 1 & & & & & & & \\
\hline & $\mathrm{C}$ & $0.701 * * *$ & $0.582 * * *$ & 1 & & & & & & \\
\hline \multirow[t]{5}{*}{ Resilience $^{b}$} & $\mathrm{D}$ & $0.526^{* * *}$ & $0.530 * * *$ & $0.452 * * *$ & 1 & & & & & \\
\hline & $\mathrm{E}$ & $0.474 * * *$ & $0.390 * * *$ & $0.376^{* * *}$ & $0.682 * * *$ & 1 & & & & \\
\hline & $\mathrm{F}$ & $0.470 * * *$ & $0.400 * * *$ & $0.426 * * *$ & $0.569 * * *$ & $0.622 * *$ & 1 & & & \\
\hline & G & $0.257 * * *$ & $0.199 * *$ & $0.227 * *$ & $0.228 * *$ & $0.436 * * *$ & $0.365 * * *$ & 1 & & \\
\hline & $\mathrm{H}$ & $0.265 * * *$ & $0.182 * *$ & $0.225 * *$ & $0.195 * *$ & $0.208 * *$ & $0.292 * * *$ & $0.161 *$ & 1 & \\
\hline Turnover intention $^{c}$ & $\mathrm{I}$ & $-0.484 * * *$ & $-0.190 * *$ & $-0.414 * * *$ & $-0.275 * * *$ & $-0.245 * * *$ & $-0.265 * * *$ & -0.049 & $-0.175 * *$ & 1 \\
\hline
\end{tabular}

${ }^{*} \mathrm{p}<0.05,{ }^{* *} \mathrm{p}<0.01, * * * \mathrm{p}<0.001$.

${ }^{\mathrm{a}} \mathrm{A}$ : fit, B: link, C: sacrifice.

${ }^{\mathrm{b}} \mathrm{D}$ : toughness, E: patience, F: positive tendency, G: support, H: spirituality.

'I: turnover intention.

Data was analysed by Pearson correlation statistics. 
Table 4. Factors Affecting Turnover Intentions

\begin{tabular}{lrrrrrr}
\hline \multicolumn{1}{c}{ Variable } & $\mathrm{B}$ & $\mathrm{SE}$ & $\beta$ & $\mathrm{t}(\mathrm{p})$ & $\mathrm{TOL}$ & $\mathrm{VIF}$ \\
\hline (Constant) & 5.501 & 0.287 & & 19.143 & & \\
Fit & -0.562 & 0.105 & -0.463 & $-5.359^{* * *}$ & 0.450 & 2.223 \\
Link & 0.251 & 0.089 & 0.214 & $2.825^{* *}$ & 0.586 & 1.708 \\
Sacrifice & -0.299 & 0.118 & -0.214 & $-2.525^{*}$ & 0.469 & 2.134 \\
F (p) & & & $26.973^{* * *}$ & & \\
Adjusted R & & & 0.262 & & \\
Durbin-Watson & & & & & \\
\hline
\end{tabular}

SE: standard error, VIF: variance inflation factors, TOL, tolerance. ${ }^{*} \mathrm{p}<0.05,{ }^{* *} \mathrm{p}<0.01, * * * \mathrm{p}<0.001$

highest at 3.57, and sacrifice scored the lowest at 3.06. According to the studies of Kang and Jung ${ }^{15)}$ and Kim et al. ${ }^{1)}$ regarding nurses, job embeddedness (fit, link, and sacrifice) averaged 3.27 and 2.97, respectively. Dental hygienists had a better interaction with their peers than other nurses. Resilience scored 3.58, and among the sub-domains, support, patience, and positive tendency scored the greatest, in increasing/decreasing order. Dental hygienists were well-connected with other people who could support them even under stressful situations. The turnover intention was 3.53 , slightly higher than Yoon et al.'s result ${ }^{16)}$ of 3.23 .

Second, among the general characteristics, there were differences in job embeddedness, resilience, and turnover intention according to age, marriage, total dental clinic career, education degree, and position. The higher the age and education level, the higher the job embeddedness and resilience and the lower the turnover intention. The higher the age and level of education, the more they feel that they fit into the work and environment they are performing in and the more they seem to overcome and adapt to individual stress or adversity. Moreover, as work experience increases, a sense of stability for the organization and work is developed, and job embeddedness is high due to smooth interpersonal relations. According to the general characteristics of the study of Kang and Jung ${ }^{15)}$, higher job embeddedness was associated with more married people, full-time workers, senior nurses, and older age and career. This is the same as the result of this study. The study of Kim and $\mathrm{Ryu}^{7)}$ also showed that the higher the age and salary level, the lower the turnover intention. The more experience you have, the higher your income. However, even if you move to another place, you cannot guarantee the income. In addition, there are few dentists who want a dental hygienist with a lot of experience. For these reasons, it seems that more careers are associated with a lower turnover intention.

Third, the fit, link, and sacrifice of job embeddedness appeared to be factors affecting turnover intention. Fit and sacrifice had a negative effect on turnover intention, as seen in several studies ${ }^{9,15,17,18)}$. The more a dental hygienist perceives personal values, achievement of professional goals, and values as similar or appropriate to their job duties and organizational requirements, the lower the turnover intention. Furthermore, the more an individual perceives the material and psychological damages that occur when he quits his job, the lower the turnover intention. In the research of Mitchell et al. ${ }^{9)}$ and Park and $\mathrm{Lee}^{17)}$, link had no significant effect on turnover intention, but the present study had a positive effect, similar to the research of Ko and Lee ${ }^{8}$. If the interpersonal relationship is good, it is interpreted as having a positive effect on turnover intention because there is no fear of adapting to the new environment. In order to reduce the dental hygienist's turnover intention, it is necessary to hire employees who fit the dental clinic's values and characteristics well. In addition, incentives and promotions should be actively considered so that employees with high links that have a positive impact on the organization do not deviate from their members. Resilience did not affect turnover intention. A positive response to overcoming an individual's stress or adversity does not appear to have a significant impact on job turnover. However, in the study of Seo and $\mathrm{Cho}^{19)}$ regarding nurses, resilience was a factor 
influencing turnover intention, so further research is likely needed in the future.

It is difficult to draw generalizations from this cross-sectional survey, and job satisfaction, organizational commitment, job alternatives and job search suggested by Mitchell et al. ${ }^{9)}$ were excluded. Therefore, it is necessary to compare the influence of these variables on the turnover. Turnover intention is not yet expressed in action but is a predictor that can lead to turnover ${ }^{20)}$. By looking at the factors of turnover intention, it is therefore necessary to lower the turnover to secure competent human resources and make them willing to work hard in the field ${ }^{1)}$. Based on the results of this study, it is necessary to develop training and management programs to secure the core talents of dental clinics by minimizing the causes of the voluntary resignation of competent dental hygienists and to maximize their capabilities.

\section{Notes}

\section{Conflict of interest}

No potential conflict of interest relevant to this article was reported.

\section{Ethical approval}

This study was approved by the Institutional Review Board of Baekseok Culture University (2-7008132-A$\mathrm{N}-01)$.

\section{Author contributions}

Conceptualization: Ji-Min Hwang, Ji-Hyoung Han.

Data acquisition: Ji-Min Hwang, Ji-Hyoung Han. Formal analysis: Ji-Min Hwang. Supervision: Ji-Min Hwang, Ji-Hyoung Han. Writing-original draft: Ji-Min Hwang, Ji-Hyoung Han. Writing-review \& editing: Ji-Hyoung Han.

\section{ORCID}

Ji-Min Hwang, https://orcid.org/0000-0003-2199-8319

Ji-Hyoung Han, https://orcid.org/0000-0003-1613-2879

\section{References}

1. Kim JK, Kim MJ, Kim SY, Lee KA: Effects of general hospital nurses' work environment on job embeddedness and burnout. J Korean Acad Nurs Adm 20: 69-81, 2014. https://doi.org/10.11111/jkana.2014.20.1.69

2. Moon SJ, Han SS: A predictive model on turnover intention of nurses in Korea. J Korean Acad Nurs 41: 633-641, 2011. https://doi.org/10.4040/jkan.2011.41.5.633

3. Yoo MJ, Kim JK: A structural model of hospital nurses' turnover intention: focusing on organizational characteristics, job satisfaction, and job embeddedness. J Korean Acad Nurs Adm 22: 292-302, 2016. https://doi.org/10.11111/jkana.2016.22.3.292

4. Retrieved August 3, 2020, from http://www.dailydental.co. $\mathrm{kr} /$ news/article.html?no=108818(2019).

5. Bae SM, Kim HK: A status of determinant of the intention to turnover for dental hygienists. J Korea Acad-Ind Cooper Soc13: 5986-5992, 2012. https://doi.org/10.5762/KAIS.2012.13.12.5986

6. Lee SJ, Woo HJ: Structural relationships among job embeddedness, emotional intelligence, social support and turnover intention of nurses. J Korean Acad Nurs Adm 21: 32-42, 2015. https://doi.org/10.11111/jkana.2015.21.1.32

7. Kim YS, Ryu SA: Influence of job embeddedness factors on turnover intention of nurses in small and medium sized general hospitals. J Korean Acad Nurs Adm 22: 158-166, 2016.

https://doi.org/10.11111/jkana.2016.22.2.158

8. Ko KJ, Lee SK: Influence of resilience and job embeddedness on turnover intention in general hospital nurses. J Korean Acad Nurs Adm 25: 362-372, 2019. https://doi.org/10.11111/jkana.2019.25.4.362

9. Mitchell TR, Holtom BC, Lee TW, Sablynski CJ, Erez M: Why people stay: using job embeddedness to predict voluntary turnover. Acad Manag J 44: 1102-1121, 2001. https://doi.org/10.5465/3069391

10. Baek YS: The effects of resilience on job satisfaction and organizational commitment: with a focus on members of Gyeongbuk Headquarters of KORAIL. Ordo Econ J 18: 129-146, 2015.

11. Lee SY, Yu BC: Relationship between occupational stress 
and work-related factors in dental hygienists. J Dent Hyg Sci 11: 553-562, 2011.

12. Connor KM, Davidson JR: Development of a new resilience scale: the Connor-Davidson Resilience Scale (CD-RISC). Depress Anxiety 18: 76-82, 2003. https://doi.org/10.1002/da.10113

13. Baek HS: Reliability and validity of the Korean version of the Connor-Davidson Resilience Scale (K-CD-RISC). Unpublished master's thesis, Eulji University, Daejeon, 2010.

14. Mobley WH: Employee turnover, causes, consequences, and control. Addison-Wesley Publishing, Reading, pp. 1-212, 1982.

15. Kang EH, Jung J: Influence of nurse's job embeddedness and job stress on turnover intention. Health Welf 22: 221-243, 2020.

https://doi.org/10.23948/kshw.2020.03.22.1.221

16. Yoon MS, Lee KH, Choi MS: A study on the turnover intention and job satisfaction of dental hygienists. J Dent Hyg Sci 6: 147-152, 2006.

17. Park KK, Lee KE: A study on the relationship between job embeddedness and turnover intention in Korea. Korean Manag Rev 33: 1423-1439, 2004.

18. Eun HR, Koo JB, Jung TY: Qualitative research of job turnover and stay, based on job embeddedness. Korean J Cult Soc Issues 24: 221-250, 2018. https://doi.org/10.20406/kjcs.2018.5.24.2.221

19. Seo MK, Cho GY: The effects of job stress, resilience and empowerment on turnover intention of hospital nurses. $\mathrm{J}$ Korean Data Anal Soc 21: 2699-2712, 2019. https://doi.org/10.37727/jkdas.2019.21.5.2699

20. Bluedorn AC: A unified model of turnover from organizations. Hum Relat 35: 135-153, 1982. https://doi.org/10.1177/001872678203500204 